\title{
REGARDING TO THE ACTIVE ROLE OF THE NATIONAL AGENCY OF FISCAL ADMINISTRATION
}

\section{Diana Cîrmaciu}

\section{Cîrmaciu}

Faculty of Law

University of Oradea, Oradea, Romania

*Correspondence: Diana Cîrmaciu, University of Oradea, 26 Gen. Magheru Street, Oradea, Romania

e-mail: diana.cirmaciu@rdslink.ro

\begin{abstract}
The National Agency for Fiscal Administration was incorporated on 1 October 2003 subordinated to the Ministry of Public Finances, by Government Ordinance no. 86/2003, as a specialized body of the central public administration. Starting with January 2004 it became operational, acquiring the capacity of institution with its own legal personality, by splitting the directorates in charge of the state income administration within the Ministry of Public Finances.
\end{abstract}

Keywords: National Agency for Fiscal Administration, politics of fiscal administration, transparency

\section{Introduction:}

To guarantee the good functioning of Romanian society the role of A.N.A.F is to collect efficiently the budgetary incomes.

In the context of perpetuation of the effects of the economical crisis attracting public incomes is a major challenge for A.N.A.F, because collecting these becomes more and more difficult in the condition of restriction of economical activities, of a fragile voluntary compliance and in the condition of a growing fiscal evasion.

The efficiency of attracting resources cannot be realized without the voluntary compliance of the tax-payer and without modern and quality assistance services offered by the Agency. During the assistance activities offered for the tax-payers, A.N.A.F. and implicitly the public officers of fiscal administration are going to respect the following principles: the principle of equality before the law and before public authorities, the principle of no discrimination, of access to information of public interest, of free fiscal assistance offered for the tax-payer, of transparency, of adjustment of fiscal administration according to the request of the tax-payer, of respect and consideration towards the tax-payer and of confidentiality.

The budgetary incomes collecting procedures promoted by A.N.A.F. must be simplified, coherent, in order to serve the interests of a healthy, equitable and competitive business environment. The simplification and/or modernization of fiscal procedure is realized through the continuous extension of use of informatics (this way the modern applications have facilitated the fulfilment of fiscal obligations in term, diminishing "losing time" by the offices of the competent fiscal administrations). The accentuation of the simplifying politics of the procedures assessed the re-examination and reformulation of declarations and forms and also the elimination of some declarations.

In sustaining these objectives, along the time, A.N.A.F. has implemented different politics of fiscal administration which have contributed also to the prevention of fiscal evasion 
- infractions generating negative effects in the structure of budgetary incomes, in the business environment, etc.

In order to fight against fiscal fraud the actions of A.N.A.F. are aiming to verify as a priority those tax-payers who can represent important potential of fiscal evasion, selected based on some risk analyses, but also on some prudential supervision of the higher risk domains of fiscal evasion like the domain of intra-communitarian acquisitions ${ }^{1}$, of the excise taxable products, of the import-export operations etc.

In the same time, for the following period, the actions of A.N.A.F. must aim also combating cross-border fiscal evasion, multinational fraud and to assure the necessary basis to implement the Schengen Agreement.

Even more, to prevent and fight against not declaring or under declaration of social contributions and to fight against the phenomenon of illegal work there are organized periodically some cooperation programs (common control operations) with the Labour Inspectorate. The controlling act is permanently developed through the professional training of the employees, during the whole time of fiscal control, the inspectors of fiscal control having the obligation to work professionally, proving rectitude and objectivity in relation to tax-payers and to other persons with whom they meet during fulfilling their service activity. Also to prevent and to fight against nonconformity of the tax-payers towards fiscal obligations (declarations and payments), A.N.A.F. will monitor the newly founded tax-payers (registered for VAT), will try to improve the efficiency of administrative sanctions and to improve the cooperation with the units of research and penal prosecution.

A.N.A.F. will have to prevent fraud from the collecting phase of fiscal debts, analyzing permanently the solvency indicators of the tax-payers in order to prevent the accumulation of more debts compared with the patrimonial situation. This way the appearance of the impossibility of enforcement procedure will be avoided.

In order to accomplish efficient analyses and for a better foundation of the measures disposed through a controlling action, the inspectorate of fiscal control will promote the principles of integrity in exercising its function, of objectivity in making establishments and establishing the applied measures, of legality of the control procedure, of confidentiality and of competency.

The National Agency of Fiscal Administration has the following main objectives ${ }^{2}$ :

- realizing the incomes of the general budget consolidated from taxes, fees, social contributions and any other amounts which have to be paid to the budget of the state, through the continuous improvement of the voluntary conformity level of the tax-payers;

- the unitary application of the foresights of fiscal legislation;

- service of information and assistance delivery for the tax-payers for the understanding and correct application of fiscal legislation;

- the constant improvement of efficiency in collecting budgetary incomes;

- guaranteeing reliability for the tax-payer in the integrity and impartiality of fiscal administration;

\footnotetext{
${ }^{1}$ In order to prevent and fight against intra-communitarian fiscal evasion and fiscal fraud, A.N.A.F. must take into consideration the intensification of cooperation with other member states through special measures of administrative cooperation activities, respectively:

- the initiation of multilateral controls and the continuous participation by the controls initiated by other states; - participation through the intra-communitarian exchange network of information Eurofisc, dedicated for operative exchange of data regarding to suspicious intra-communitarian transactions;

- the increasing of efficiency in valuing data transmitted by Eurofisc, through the intensification af the verifying actions developed by the territorial structures.

${ }^{2}$ Art. 4 paragraph 1 of G.D. No. 109 from 18.02.2009 regarding to the organization and functioning of the National Agency of Fiscal Administration published in the Official Monitor No. 126/02.03.2009, with the ulterior modifications and completions by G.D. No. 566 from 01.06 .2011 published in the Official Monitor No. 405/09.06.2011.
} 
- preventing and fighting against evasion and fiscal fraud;

- training of competent and motivated human resources;

- protecting the fiscal and financial interests of the European Union, etc. attributions ${ }^{3}$ :

In realizing the above mentioned objectives, A.N.A.F. has mainly the following

1. ellaborates and applies procedures regarding to voluntary payment and the establishment of payment means, together with the special directions of the Ministry of Public Finances;

2. ellaborates and applies, through competent units, procedures regarding to other methods of compensations of budgetary obligations administrated by it;

3. participates by the estimation of budgetary incomes which are administrated by it and makes proposals regarding to the income level which can be collected from the tax-payers, based on registered dates, on macro-economical indicators, fiscal politics and on the actual legislation regarding to taxes, fees, social contributions and other budgetary incomes;

4. delivers for the Ministry of Public Finances the necessary information for the foundation of estimation of incomes which can be collected from the tax-payers;

5. delivers for the special structures of the Ministry of Public Finances the necessary information for the foundation of calculation of the contribution of Romania to the budget of the European Union;

6. assures the unitary, correct and not discriminating application of the legal foresights regarding to taxes, fees, social contributions and other budgetary incomes, the collection of budgetary incomes, the application of the prerogatives established by law, through the equitable treatment for all the tax-payers, the use of new technologies in sustaining the management of the National Agency of Fiscal Administration and the improvement of the relation with the tax-payers;

7. participates, together with the special directives from the Ministry of Public Finances by the elaboration of the projects of normative documents regarding to the establishment of budgetary incomes;

8. sustains the encouragement of voluntary conformation of the tax-payers through the development of the services offered for them, aiming to facilitate the fulfilment of fiscal obligations;

9. offers guidance for the tax-payers in the application of fiscal legislation and of the foresights of the agreements to avoid double taxation with the help of the territorial fiscal units;

10. represents the state in front of the court and of the units of penal prosecution, as subject with rights and obligations regarding to judicial fiscal relations and other activities of the agency, directly or represented by the general directions of the territorial public finances and of the capital Bucharest, based on the transmitted warrant; the resignation of means of appeal, in the litigations which are connected to judicial fiscal reports, will be made according to the procedure established by the orders of the president of the National Agency of Fiscal Administration.

A.N.A.F. continues to develop its activity based on the efficiency principles of the activity of fiscal administration, on the principle of unitary treatment, of respect and transparency towards the tax-payers.

The primary axes of the politics of fiscal administration focus on three important action directions ${ }^{4}$ :

- fighting against fiscal evasion and against any other form of avoiding the declaration and payment of fiscal obligations;

\footnotetext{
${ }^{3}$ Ibidem, art. 4 paragraph 2.

${ }^{4}$ www.anaf.ro - National Agency of Fiscal Administration, datum 4 March 2013, 15.00 o'clock.
} 
- the improvement of the efficiency and dynamics of collecting and in the same time reducing the costs of collection;

- the encouragement of voluntary conformation in order to assure a quick collection with reduced costs.

The active role of A.N.A.F. in the procedure of fiscal administration will be developed also through the future implementation of control of electronic commerce. These kinds of control procedures (respectively, the necessary informatics application to analyze internet transactions) will be developed mostly with the help of European funds.

Through its politics A.N.A.F aims to develop partnership with the tax-payers, according special attention also to create some consulting mechanisms with the representatives of the subjects of taxation. Through the increasing of efficiency of communication there will be a complex process of transparency of the activity and of development of trust in the quality of the services offered by fiscal administrations. A.N.A.F. must remain the promoter of organizing communication sessions, thematic meetings in order to know and unitarily apply fiscal legislation, editing flyers, brochures to transmit information to the tax-payers.

We must mention that A.N.A.F., in the actual economic context continues to face some important challenges in order to modernize its activity. They tried to identify some weak points of the agency, where they are operating in the future in order to eliminate malfunctions, to strengthen the fiscal system and in order to use the given resources at maximal capacity and in efficient conditions. These problems are concerning:

- continuously, the reduced level of voluntary conformation and for this reason, the keenly felt need of action in order to fight against fiscal evasion, against any kind of measures of avoiding declarations and payments and in order to improve the services offered to tax-payers and to diminish the conformation costs;

Fiscal administration must develop every kind of fiscal administrative tasks, including the services offered to tax-payers, elaborate inspections and investigations - through which it is offered the possibility to plan, coordinate and evaluate in an efficient manner all those activities which are able to influence the conformation of the tax-payers.

- the actual organizational structure, especially that of the territorial agency which imply high administrative costs, caused the foundation of the high number of fiscal organs, all the counties being similarly treated without taking into consideration the dimensions and importance of each of them under the aspect of their economical share, or of the number of tax-payers etc.

- the inefficient distribution of employees among the different activities of fiscal administration, as well as among the different units of territorial level, without respecting from one county to the other the same proportion between the number of employees and the number of the administered tax-payers or the realized incomes;

We must underline the fact that the efficiency of the fiscal system is burdened also by the great number and gravity which are occupied by non-fiscal activities or by those which are not subordinated to the aim of collecting budgetary incomes. Furthermore, the number of employees assigned to different structures of territorial level, are not well-proportioned with some indicators like the number of tax-payers or the realized incomes.

To consolidate the necessary legal frame in order to fight fiscal evasion and because of the engagements assumed by Romania in relation to the International Monetary Fund, the Government adopted the Urgent Ordinance No. 74/2013 .

With this normative document it is aimed to regulate the following aspects:

\footnotetext{
${ }^{5}$ O.U.G. No. 74/2013 regarding to some measures to improve and reorganize the activity of the National Agency of Fiscal Administration, and for the modification and completion of some normative documents published in the Official Monitor No. 389/29.06.2013.
} 
- the creation of regional level in order to reduce the number of reports to the main office of A.N.A.F., to improve plans and controls, to reduce the cost of collection and to create some more balanced units in the perspective of economic share and of share in collecting incomes;

- the creation of anti-fraud structure through the reorganization of operative control among the own system of A.N.A.F.. Taking into consideration the necessity of recovering with celerity the damages caused at the budget of the state through criminal activity of fiscal evasion, and also the necessity of the training of employees who are dedicated to fight against this phenomenon, the anti-fraud structure will take over also activities of penal investigations. This measure is justified by the necessity of coordination by a single unit of the whole activity, in order to concentrate information and to use them efficiently, through reducing administrative barriers and to obtain immediate results. It is taken into consideration the example of some developed European countries, where this kind of structure which combine penal investigation with administration/fiscal research and obtain great results in fighting against the phenomenon of fiscal evasion.

In a concrete manner, by the Agency there is founded the general Direction of fiscal anti-fraud, structure without judicial personality, with attributions in preventing and fighting against documents and actions of fiscal evasion, fiscal fraud and customs fraud. The direction id coordinated by a vice-president with rank of under-secretary of state, named by the decision of the prime minister and lead by a general inspector of anti-fraud, helped by a general deputy inspector of anti-fraud.

Among the central structure of the general Direction of fiscal anti-fraud, near the structures of prevention and control, there is the Direction of combating fraud, which offers specialized technical support to the prosecutor in the development of penal pursuit in the cases with object of economic-financial infraction. In order to this the anti-fraud inspectors of this direction are sent to the prosecuting magistracy, according to law, as specialists.

In exercising their duties, the anti-fraud inspectors of the Direction of combating fraud are making, according to the disposals of the prosecutor: technical-scientific establishments, containing proving materials, according to law; financial investigations in order to block goods; any other controls in fiscal matters ordered by the prosecutor ${ }^{6}$.

- assuring the autonomy of the General Direction of Customs, as part of A.N.A.F., in exercising the special functions of customs: the security of the external border of the European Union, doing the customs operations, fighting against drug trading and against trading of counterfeit goods etc.;

- the implementation of a new strategy of human resources and the simplification of the decisional process. This measure can be realized through the redistribution of the employees towards the critical domains (anti-fraud, fiscal inspection, IT, judicial) or towards fiscal organs with the highest load of work, and at the other hand by dismiss of those who are not corresponding from professional point of view and from the point of view of integrity. In the same time through reducing with up to $30 \%$ the management functions the decisional process will be quicker and there will be savings in order to use the budgetary funds for the costs with the employees.

\section{Conclusions}

The fiscal administration must continuously deliver quality services for the users, because they are expecting quick, correct and objective solutions for their documents. The decision-making must be quick, steady and transparent. The principle of transparency is referring not only to the modalities but also to the factors which stand on the bases of the decisions.

\footnotetext{
${ }^{6}$ Art. 3 paragraph 4 of O.U.G. No. 74/2013.
} 
Last, but not at least, A.N.A.F. also fulfills an acting role in international relations, the adherence of Romania to the European Union obliging the agency to participate in an active way by the European decisional process through the promotion of some of their own ideas and interests. The representatives of A.N.A.F. have participated and are continuously implied in a various range of activities regarding to international cooperation: reunions of workgroups organized at the level of European institutions (visits and workshops developed through the program FISCALIS, events organized by the Intra-European Organization of the Fiscal Administration, and also activities of the projects developed on bilateral bases together with other fiscal administrations.

\section{Bibliography:}

1. Government Ordinance no. 74/2013;

2. Nadia Cerasela Aniţei, Drept financiar, Editura Universul juridic, Bucureşti, 2011.

\section{Web resources:}

1. www.anaf.ro - National Agency of Fiscal Administration 